\title{
Densificação, tamanho de grãos e condutividade elétrica da céria-samária
}

\section{(Densification, grain size and electrical conductivity of samaria-doped ceria)}

\author{
S. L. Reis, E. N. S. Muccillo \\ Instituto de Pesquisas Energéticas e Nucleares - IPEN, R. do Matão, Travessa R, 400, \\ Cidade Universitária, S. Paulo, SP 05508-000 \\ shirley.reis@usp.br,enavarro@usp.br,
}

\begin{abstract}
Resumo
A céria contendo $20 \% \mathrm{~mol}$ samária é um eletrólito sólido proposto para uso em células a combustível de óxido sólido que operam em temperaturas intermediárias $\left(\sim 500\right.$ a $\left.700{ }^{\circ} \mathrm{C}\right)$, devido sua alta condutividade iônica. Um dos fatores limitantes para isto é sua relativamente baixa sinterabilidade. Neste trabalho foram utilizados dois métodos alternativos de sinterização com a finalidade de obter amostras densas, microestrutura homogênea e tamanho de grãos controlado. Outro objetivo foi relacionar os efeitos observados na microestrutura e na densificação com a condutividade elétrica das amostras sinterizadas. Para isto foi utilizada a $\mathrm{Ce}_{0,8} \mathrm{Sm}_{0,2} \mathrm{O}_{1,9}$ comercial, conformada uniaxial e isostaticamente, e sinterizada ao ar. As amostras sinterizadas foram analisadas por diversas técnicas. Resultados de medidas da densidade aparente revelaram que ambos os métodos são eficazes para a obtenção de cerâmicas com densidade relativa superior a 92\%. A condutividade elétrica dos grãos e dos contornos de grão são também similares nas diversas amostras estudadas, apesar dos tamanhos dos grãos serem diferentes.
\end{abstract}

Palavras-chave: densificação, tamanho de grão, condutividade elétrica, céria-samária.

\begin{abstract}
Ceria containing $20 \mathrm{~mol} \%$ samaria is a solid electrolyte with potential application in solid oxide fuel cells operating at intermediate temperatures ( $\sim 500$ to $700{ }^{\circ} \mathrm{C}$ ) due to its high ionic conductivity. One of the main concerns related to this solid electrolyte is the relatively low sinterability. In this work, two alternative sintering methods were used to obtain ceramic samples with high density, homogeneous microstructure and controlled grain size. Other purpose of this work was to correlate the observed effects in the microstructure and densification with the electrical conductivity of sintered samples. Commercial $\mathrm{Ce}_{0.8} \mathrm{Sm}_{0.2} \mathrm{O}_{1.9}$ was used as starting material. The consolidation was accomplished by uniaxial and isopressing followed by sintering in air. Several techniques were used for sample characterization. Apparent density results revealed that both sintering methods were able to produce samples with relative density higher than 92\%. The electrical conductivity of grains and grain boundaries were similar in these samples, although different grain sizes were obtained.
\end{abstract}

Keywords: densification, grain size, electrical conductivity, samaria-doped ceria.

\section{INTRODUÇÃO}

Soluções sólidas de céria contendo terras raras, principalmente gadolínio e samário, têm sido muito estudadas nos últimos anos para aplicação em células a combustível de óxido sólido (SOFC), tanto como eletrólito sólido como componente de eletrodos. Essas soluções sólidas apresentam alta condutividade iônica a temperaturas intermediárias (500 a $750{ }^{\circ} \mathrm{C}$ ) possibilitando reduzir a temperatura de operação, e resultando em redução do custo deste dispositivo [1].

A ceria-samária é um dos principais candidatos para uso como eletrólito sólido em SOFC devido sua

Tabela I - Resultados de densificação obtidos para a $\left(\mathrm{CeO}_{2}\right)_{0,8}\left(\mathrm{SmO}_{1,5}\right)_{0,2}$ de acordo com o método de síntese.

[Table I - Results on densification of $\left(\mathrm{CeO}_{2}\right)_{0.8}\left(\mathrm{SmO}_{1.5}\right)_{0.2}$ prepared by several methods.]

\begin{tabular}{ccccc}
\hline Técnica de síntese & $\begin{array}{c}\text { Temperatura de sinterização } \\
\left({ }^{\circ} \mathrm{C}\right)\end{array}$ & $\begin{array}{c}\text { Tempo de } \\
\text { sinterização } \\
(\mathrm{h})\end{array}$ & $\begin{array}{c}\text { Densidade relativa } \\
(\%)\end{array}$ & Referência \\
\hline Co-precipitação & 1550 & 3 & $>90$ & 2 \\
Co-precipitação & 1300 & 4 & 97 & 3 \\
Hidrotérmica & 1400 & 10 & 95 & 4 \\
Sol-gel & 1400 & 10 & 95 & 5 \\
Combustão & 1300 & 10 & 95 & 6 \\
Co-precipitação & 1400 & 5 & 97 & 7 \\
\hline
\end{tabular}


comparativamente alta condutividade iônica. Um dos principais problemas associados com os eletrólitos sólidos à base de céria é a facilidade de redução do $\mathrm{Ce}^{4+}$ para $\mathrm{Ce}^{3+}$ em atmosferas redutoras e altas temperaturas. Outro fator limitante é a dificuldade em obter cerâmicas densas, mesmo com tratamentos térmicos em altas temperaturas e empregando pós sintetizados quimicamente, como exemplificam os dados listados na Tabela I.

A diminuição na temperatura de operação de uma célula a combustível para $\sim 500^{\circ} \mathrm{C}$ pode ser suficiente para minimizar, ou até mesmo eliminar, a reação de redução da céria em atmosferas redutoras [8]. Assim, persistem os esforços no sentido de melhorar sua sinterabilidade. As abordagens mais comuns, neste caso, são a otimização da síntese de pós ultrafinos e o emprego de aditivos de sinterização. Outra possibilidade, pouco explorada, é a utilização de métodos de sinterização diferentes do convencional.

Esposito e Traversa [9] fizeram uso da sinterização rápida em pós sintetizados pelo método da co-precipitação obtendo alta densificação ( 96\% da densidade teórica) e tamanho médio de grãos de $150 \mathrm{~nm}$ após sinterização a $1300-1400{ }^{\circ} \mathrm{C}$. Bellino [10] e Anselmi-Tamburini [11] utilizaram a técnica de sinterização por descarga de plasma ("spark plasma sintering") e também obtiveram densidades relativas entre $92 \%$ e $98 \%$ e tamanho médio de grãos inferiores a $100 \mathrm{~nm}$. Estas técnicas, entretanto, têm restrito potencial para aplicações tecnológicas.

Recentemente, Chen e Wang [12] mostraram que cerâmicas densas podem ser obtidas por um processo por eles denominado sinterização em duas etapas ("Two Step Sintering", TSS), que tem como premissa a obtenção de cerâmicas densas e com tamanho de grãos reduzidos, porque suprime o crescimento de grãos que ocorre no estágio final de sinterização. Segundo os autores, a eficácia da densificação neste caso se deve à supressão da migração dos contornos de grão ao mesmo tempo em que é mantida a difusão via contornos de grão. Para que o processo seja otimizado os autores mostraram que uma densidade relativa em torno de $75 \%$ deve ser obtida na primeira etapa de sinterização quando esta se processa por reações em estado sólido, e $85 \%$ para sinterizações que ocorrem na presença de fase líquida [13]. Este método de sinterização em duas etapas foi utilizado por alguns pesquisadores para materiais diversos tais como, $\mathrm{Al}_{2} \mathrm{O}_{3}, \mathrm{ZnO}, \mathrm{BaTiO}_{3}$ e $\mathrm{Si}_{3} \mathrm{~N}_{4}$, dentre outros [14-23]. Para a céria contendo gadolínia os resultados da sinterização em duas etapas mostraram ser possível obter cerca $92 \%$ da densidade teórica e grãos com tamanho sub-micrométrico [24].

$\mathrm{Na}$ literatura científica é também possível encontrar alguns trabalhos nos quais um método não tão recente, mas também denominado sinterização em duas etapas foi utilizado com a finalidade de obter melhor homogeneidade na microestrutura de poros antes da sinterização. Esse método tradicional de sinterização em duas etapas (TSS-t) foi empregado com sucesso na sinterização do $\mathrm{MgO}, \mathrm{ZnO}$ e $\mathrm{Al}_{2} \mathrm{O}_{3}$ [25-27]. No caso específico da alumina foi mostrado que, após a primeira etapa de sinterização a $800{ }^{\circ} \mathrm{C}$ por $50 \mathrm{~h}$, a microestrutura dos compactos apresentou maior uniformidade no tamanho e na distribuição da porosidade, quando comparada com a microestrutura original. Após a segunda etapa de sinterização a $1450{ }^{\circ} \mathrm{C}$ houve também homogeneização da microestrutura, e os compactos atingiram alta densidade relativa $(99 \%)$, tamanho de grão relativamente pequeno $(\sim 1,2 \mu \mathrm{m})$ e distribuição estreita de tamanho.

Após a sinterização, independentemente do método utilizado, as cerâmicas policristalinas são basicamente constituídas por grãos e interfaces. Há muito é sabido que as interfaces entre diferentes grãos e fases são importantes na determinação de muitas propriedades dos materiais cerâmicos. As interfaces constituem imperfeições bidimensionais com propriedades próprias, tais como composição, orientação e estrutura [28]. Numa cerâmica policristalina, diferentes tipos de interface podem coexistir em decorrência dos diversos tipos de defeitos possíveis (fases secundárias, microdomínios, inclusões, segregação de dopantes e constituintes majoritários, porosidade etc). Do ponto de vista das propriedades elétricas, as interfaces são regiões muito importantes, que podem até definir o comportamento dos materiais. Para o caso específico dos condutores de íons oxigênio, como a céria contendo aditivos, as interfaces exercem papel fundamental no bloqueio aos portadores de carga resultando em diminuição da condutividade elétrica. Por essa razão, a relação entre microestrutura e condutividade elétrica continua sendo muito estudada.

Neste trabalho, a densificação, o tamanho de grãos e a condutividade elétrica da solução sólida de céria contendo $20 \%$ mol samária comercial foram estudados visando entender a importância dos métodos de sinterização em duas etapas nestas propriedades.

\section{MATERIAIS E MÉTODOS}

Como material de partida foi utilizada a solução sólida céria-samária comercial $\left(\mathrm{Ce}_{0,8} \mathrm{Sm}_{0,2} \mathrm{O}_{1,9}\right.$, Fuel Cell Materials), com área de superfície específica $36,1 \mathrm{~m}^{2} \cdot \mathrm{g}^{-1}$.

A elaboração dos corpos de prova foi realizada por compactação uniaxial seguida de isostática a frio $(\sim 140$ $\mathrm{MPa})$.

As amostras foram sinterizadas utilizando o processo de sinterização em duas etapas (TSS) e sinterização em duas etapas tradicional (TSS-t). A taxa de aquecimento foi de $2{ }^{\circ} \mathrm{C} \cdot \mathrm{min}^{-1}$ e a de resfriamento de $10{ }^{\circ} \mathrm{C} \cdot \mathrm{min}^{-1}$. Valores superiores para as taxas de aquecimento e resfriamento resultaram em formação de trincas e microtrincas nas amostras. No método de sinterização em duas etapas a amostra é inicialmente conduzida a uma alta temperatura $\left(\mathrm{T}_{1}\right)$ na qual permanece por um tempo $\left(\mathrm{t}_{1}\right)$ pequeno ou nulo sendo, em seguida, resfriada rapidamente até uma temperatura $\left(\mathrm{T}_{2}\right)$ na qual permanece por um tempo específico $\left(\mathrm{t}_{2}\right)$, em geral, mais longo que $\mathrm{t}_{1}$. $\mathrm{O}$ perfil temperatura-tempo deste método é esquematizado na Fig. 


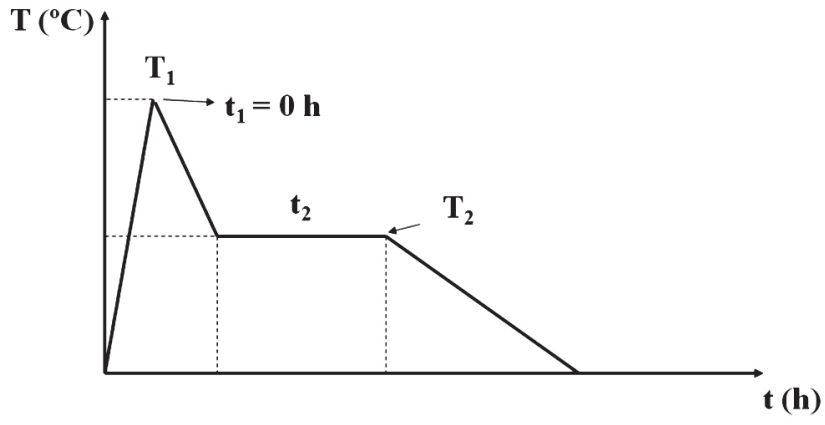

Figura 1: Representação do perfil temperatura-tempo no processo de sinterização em duas etapas.

[Figure 1: Representation of the time-temperature profile for twostage sintering.]

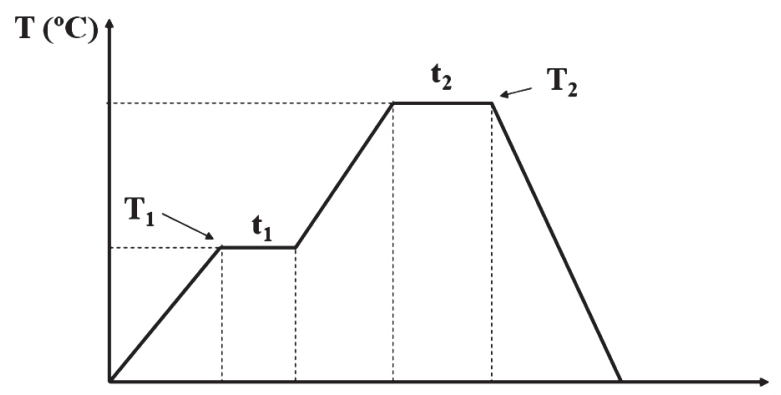

t (h)

Figura 2: Representação do perfil temperatura-tempo no processo de sinterização em duas etapas tradicional.

[Figure 2: Representation of the time-temperature profile for traditional two-stage sintering.]

1. Neste trabalho o tempo $t_{1}$ foi sempre igual a $0 \mathrm{~h}$, ou seja, as amostras foram aquecidas até $\mathrm{T}_{1} \mathrm{e}$ imediatamente resfriadas até $\mathrm{T}_{2}$.

$\mathrm{Na}$ sinterização em duas etapas tradicional, a amostra é conduzida à temperatura $\left(\mathrm{T}_{1}\right)$, na qual permanece por tempo especifico $\left(\mathrm{t}_{1}\right)$ sendo, em seguida, aquecida até a temperatura $\left(T_{2}\right)$ permanecendo por um tempo também específico $\left(t_{2}\right)$. Na Fig. 2 está esquematizado o perfil temperatura-tempo neste caso. $\mathrm{O}$ tempo $\mathrm{t}_{1}$ e a temperatura $\mathrm{T}_{2}$ foram fixados em $1 \mathrm{~h}$ e $1450^{\circ} \mathrm{C}$, respectivamente.

Após a sinterização, as amostras foram caracterizadas por medidas de densidade aparente pelo método de imersão em água utilizando o princípio de Arquimedes. Para o cálculo da densidade relativa foi utilizada a densidade teórica $\left(7,14 \mathrm{~g} . \mathrm{cm}^{-3}\right)$ da ficha JCPDF \# 28792. A dilatometria foi utilizada para estudo da retração linear (Setaram, Labsys) até $1400^{\circ} \mathrm{C}$, em atmosfera estática de ar sintético. Observação da microestrutura em microscópio eletrônico de varredura (Philips, XL30), e medidas da condutividade elétrica por espectroscopia de impedância foram também feitas para a caracterização das amostras. Para as medidas elétricas, eletrodos de prata foram aplicados por pintura, seguido de cura da resina. As medidas foram realizadas num analisador de impedância (HP 4192A) com tensão aplicada de $100 \mathrm{mV}$, na faixa de frequência de $5 \mathrm{~Hz}$ a 13 $\mathrm{MHz}$.

\section{RESULTADOS E DISCUSSÃO}

\section{Retração linear e densidade}

A Fig. 3 mostra a retração linear da céria-samária durante o ciclo de aquecimento/resfriamento realizado num dilatômetro, e a derivada da curva de aquecimento.

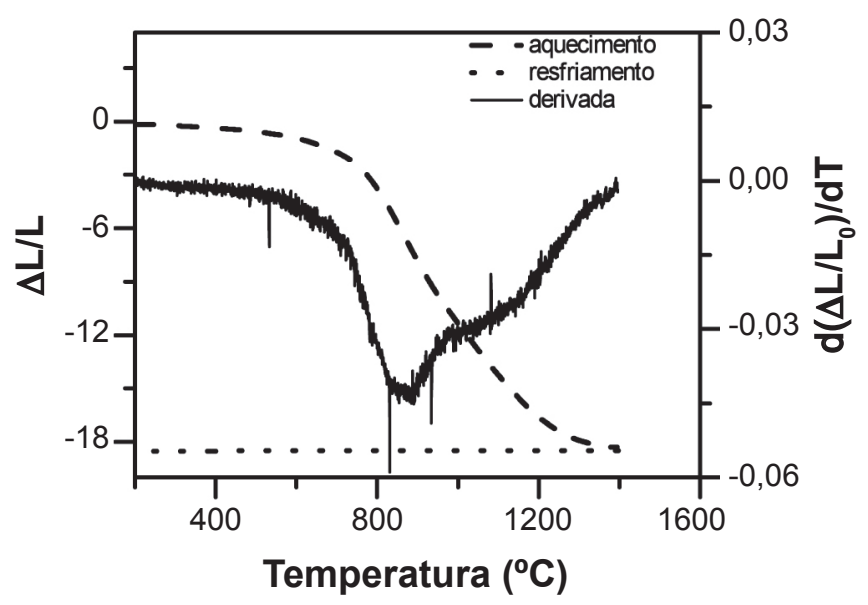

Figura 3: Retração linear da $\mathrm{Ce}_{0,8} \mathrm{Sm}_{0,2} \mathrm{O}_{1,9}$ durante o aquecimento e resfriamento, e curva da taxa de retração linear.

[Figure 3: Linear shrinkage curve of $\mathrm{Ce}_{0.8} \mathrm{Sm}_{0.2} \mathrm{O}_{1.9}$ during heating and cooling and linear shrinkage rate curve.]

A retração total obtida até $1400{ }^{\circ} \mathrm{C}$ foi de $\sim 18 \%$. A temperatura inicial de retração foi de $\sim 690^{\circ} \mathrm{C}$ e a temperatura final de $\sim 1260{ }^{\circ} \mathrm{C}$. Não foi observada variação significativa da retração linear durante o resfriamento, como esperado, pois não ocorre transformação de fase ou outros fenômenos nesta faixa de temperatura.

A taxa de retração foi obtida com a derivada da curva, que mostra dois pontos de inflexão a $\sim 884{ }^{\circ} \mathrm{C} \mathrm{e} \sim 1014{ }^{\circ} \mathrm{C}$. Como mencionado acima, a céria-samária não apresenta transformação de fase nesta faixa de temperatura, então, é possível que esta segunda mudança de inclinação esteja relacionada com alterações no mecanismo de sinterização. A temperatura na qual o compacto atinge $75 \%$ da densidade teórica é $1016^{\circ} \mathrm{C}$.

Neste trabalho procurou-se obter amostras densas e com tamanhos de grãos uniformes. Para isso, foram realizadas diversas sinterizações dos compactos onde, num primeiro momento, o objetivo era obter compactos densos variando as condições de temperatura e tempo na sinterização. Os resultados são listados na Tabela II.

A temperatura $\mathrm{T}_{1}$ onde a densidade atingida corresponde a $75 \%$ da densidade teórica é pouco superior àquela obtida por dilatometria. Em seguida, procurou-se determinar a temperatura $\left(\mathrm{T}_{2}\right)$ e o tempo $\left(\mathrm{t}_{2}\right)$ do segundo patamar. Como mostram os resultados da Tabela II, não ocorreu aumento considerável na densidade dos compactos para $\mathrm{T}_{2}$ igual a 980 e $1000{ }^{\circ} \mathrm{C}$ mesmo com o aumento do tempo $t_{2}$ até 24 h. Este resultado pode ser uma consequência das taxas de aquecimento e resfriamento empregadas. No método da 
Tabela II - Valores de densidade relativa da $\mathrm{Ce}_{0.8} \mathrm{Sm}_{0,2} \mathrm{O}_{1,9}$ sinterizada pelo método de duas etapas (TSS). [Table II - Relative density values of $\mathrm{Ce}_{0.8} \mathrm{Sm}_{0.2} \mathrm{O}_{1.9}$ sintered by the two-stage method (TSS).]

\begin{tabular}{cccc}
\hline $\begin{array}{c}\text { Temperatura/ Tempo } \\
\left({ }^{\circ} \mathrm{C} / \mathrm{h}\right)\end{array}$ & $\begin{array}{c}\text { Densidade relativa } \\
(\%)\end{array}$ & $\begin{array}{c}\text { Temperatura/ Tempo } \\
\left({ }^{\circ} \mathrm{C} / \mathrm{h}\right)\end{array}$ & $\begin{array}{c}\text { Densidade relativa } \\
(\%)\end{array}$ \\
\hline $1030 / 0$ & $75,1 \pm 1,2$ & $1300 / 0$ & $89,5 \pm 0,6$ \\
$1030 / 0+980 / 2$ & $76,3 \pm 0,8$ & $1300 / 0+1050 / 5$ & $91,8 \pm 0,6$ \\
$1030 / 0+980 / 5$ & $77,2 \pm 0,9$ & $1300 / 0+1200 / 5$ & $92,1 \pm 0,6$ \\
$1030 / 0+1000 / 5$ & $79,0 \pm 0,8$ & $1300 / 0+1250 / 5$ & $93,2 \pm 0,5$ \\
$1030 / 0+1000 / 10$ & $79,7 \pm 0,8$ & $1300 / 0+1250 / 10$ & $94,4 \pm 0,5$ \\
$1030 / 0+1000 / 24$ & $81,8 \pm 1,0$ & $1300 / 0+1275 / 5$ & $94,0 \pm 0,6$ \\
$1050 / 0+1000 / 2$ & $77,9 \pm 1,2$ & $1450 / 0$ & $93,6 \pm 0,6$ \\
$1070 / 0+1000 / 2$ & $78,9 \pm 0,7$ & $1450 / 0+1200 / 5$ & $94,3 \pm 0,7$ \\
$1070 / 0+1000 / 10$ & $79,8 \pm 1,2$ & $1450 / 0+1350 / 5$ & $95,8 \pm 0,6$ \\
$1100 / 0+1070 / 5$ & $84,0 \pm 1,2$ & $1450 / 0+1400 / 5$ & $95,7 \pm 0,8$ \\
$1200 / 0+1050 / 5$ & $88,2 \pm 0,8$ & $1450 / 0+1425 / 5$ & $98,2 \pm 0,7$ \\
\hline
\end{tabular}

sinterização em duas etapas, originalmente proposto, estas devem ser mais elevadas para que os compactos atinjam a temperatura de patamar isotérmico, $\left(\mathrm{T}_{2}\right)$, sem diminuição considerável da área de superfície específica. Contudo, Esposito e Traversa [9] não observaram diferença na microestrutura e densificação de amostras de céria contendo gadolínia sinterizadas com taxas de aquecimento entre 5 e $20{ }^{\circ} \mathrm{C} \cdot \mathrm{min}^{-1}$.

A partir desses primeiros resultados, a temperatura $\mathrm{T}_{1}$ foi gradativamente aumentada até $1450{ }^{\circ} \mathrm{C}$. Somente a partir de $\mathrm{T}_{1}$ igual a $1300{ }^{\circ} \mathrm{C}$ foi possível obter densidades relativas superiores a 92\%, após o segundo patamar. Esse valor de densidade relativa é considerado um limite para os condutores de íons oxigênio, uma vez que para valores superiores não há difusão do oxigênio molecular na estrutura permanecendo apenas a difusão do íon oxigênio.

$\mathrm{O}$ aumento da temperatura $\mathrm{T}_{1}$ de 1300 para $1450{ }^{\circ} \mathrm{C}$ proporcionou um aumento de $\sim 5 \%$ na densidade relativa. Observa-se que para $\mathrm{T}_{1}=1300^{\circ} \mathrm{C}$ e $\mathrm{T}_{1}=1450^{\circ} \mathrm{C}$ a densidade relativa sempre aumenta com $\mathrm{T}_{2}$, apesar deste ser pequeno $(\sim 2 \%)$ para $\mathrm{T}_{1}=1300{ }^{\circ} \mathrm{Ce}(<5 \%)$ para $\mathrm{T}_{1}=1450{ }^{\circ} \mathrm{C}$.

Os resultados de densidade mais significativos obtidos

Tabela III - Valores de densidade relativa da $\mathrm{Ce}_{0.8} \mathrm{Sm}_{0,2} \mathrm{O}_{1,9}$ sinterizada pelo método de duas etapas tradicional (TSS-t). [Table III - Values of relative density of $\mathrm{Ce}_{0.8} \mathrm{Sm}_{0.2} \mathrm{O}_{1.9}$ sintered by the traditional two-stage method (TSS-t).]

\begin{tabular}{cc}
\hline $\begin{array}{c}\text { Temperatura } / \text { Tempo } \\
\left({ }^{\circ} \mathrm{C} / \mathrm{h}\right)\end{array}$ & $\begin{array}{c}\text { Densidade relativa } \\
(\%)\end{array}$ \\
\hline $1000 / 1+1450 / 5$ & $93,7 \pm 1,2$ \\
$1100 / 1+1450 / 0$ & $91,6 \pm 0,9$ \\
$1100 / 1+1450 / 1$ & $91,7 \pm 0,7$ \\
$1100 / 1+1450 / 2$ & $93,4 \pm 0,6$ \\
$1100 / 1+1450 / 5$ & $95,4 \pm 1,2$ \\
$1200 / 1+1450 / 5$ & $95,1 \pm 1,2$ \\
$1250 / 1+1450 / 5$ & $94,4 \pm 1,0$ \\
\hline
\end{tabular}

para as amostras sinterizadas pelo método tradicional, TSS-t, são listados na Tabela III.

Dentre as condições estudadas, uma das que resultou em maior densificação foi com o primeiro patamar de $1100{ }^{\circ} \mathrm{C}$ por $1 \mathrm{~h}$ seguido se $1450^{\circ} \mathrm{C}$ por $5 \mathrm{~h}$.

De forma geral, os resultados de densidade mostraram que o método de sinterização em duas etapas (TSS) não é mais eficaz que o método tradicional (TSS-t).

\section{Microestrutura}

Por meio da observação de amostras por microscopia eletrônica de varredura foram determinados os valores de tamanho médio de grãos para diferentes condições de sinterização, pelo método dos interceptos.

A Fig. 4 mostra micrografias obtidas para amostras sinterizadas pelo método em duas etapas (TSS) nas condições: $T_{1}=1300{ }^{\circ} \mathrm{C}$, em temperaturas $T_{2}=1250{ }^{\circ} \mathrm{C}$ (a) e $1275^{\circ} \mathrm{C}(\mathrm{b})$, com tempo de patamar $\mathrm{t}_{2}=5 \mathrm{~h}$.

Para a amostra sinterizada na temperatura $\mathrm{T}_{2}=1250^{\circ} \mathrm{C}$ (Fig. 4a) é possível observar fração considerável de porosidade e grãos sub-micrométricos. Com o aumento de $25^{\circ} \mathrm{C}$ na temperatura $\mathrm{T}_{2}$ (Fig. 4b), a porosidade diminui de forma substancial e ocorre crescimento dos grãos, mas o tamanho médio ainda é submicrométrico.

A Fig. 5 mostra micrografias obtidas para amostras sinterizadas a $\mathrm{T}_{1}=1450{ }^{\circ} \mathrm{C}$ (a), e pelo método TSS na temperatura $\mathrm{T}_{1}=1450{ }^{\circ} \mathrm{C}$ com $\mathrm{T}_{2}=1300{ }^{\circ} \mathrm{C}$ (b) e $1400{ }^{\circ} \mathrm{C}$ (c), com tempo $\mathrm{t}_{2}$, igual a $5 \mathrm{~h}$.

Para $\mathrm{T}_{1}=1450^{\circ} \mathrm{C}$ (Fig. 5a) os grãos são sub-micrométricos e existe uma porosidade que diminui com $\mathrm{T}_{2}=1300^{\circ} \mathrm{C}$ (Fig. 5b) e $1400{ }^{\circ} \mathrm{C}$ (Fig. 5c), embora persista ainda porosidade residual. Para um aumento de $100{ }^{\circ} \mathrm{C}$ na temperatura $\mathrm{T}_{2} \mathrm{o}$ aspecto mais relevante é o aumento do tamanho dos grãos.

Para comparar o tamanho dos grãos das amostras por sinterização em duas etapas (TSS) e sinterização em duas etapas tradicional (TSS-t), também foram feitas observações por microscopia eletrônica de varredura destas últimas amostras. A Fig. 6 mostra micrografias obtidas para amostras 

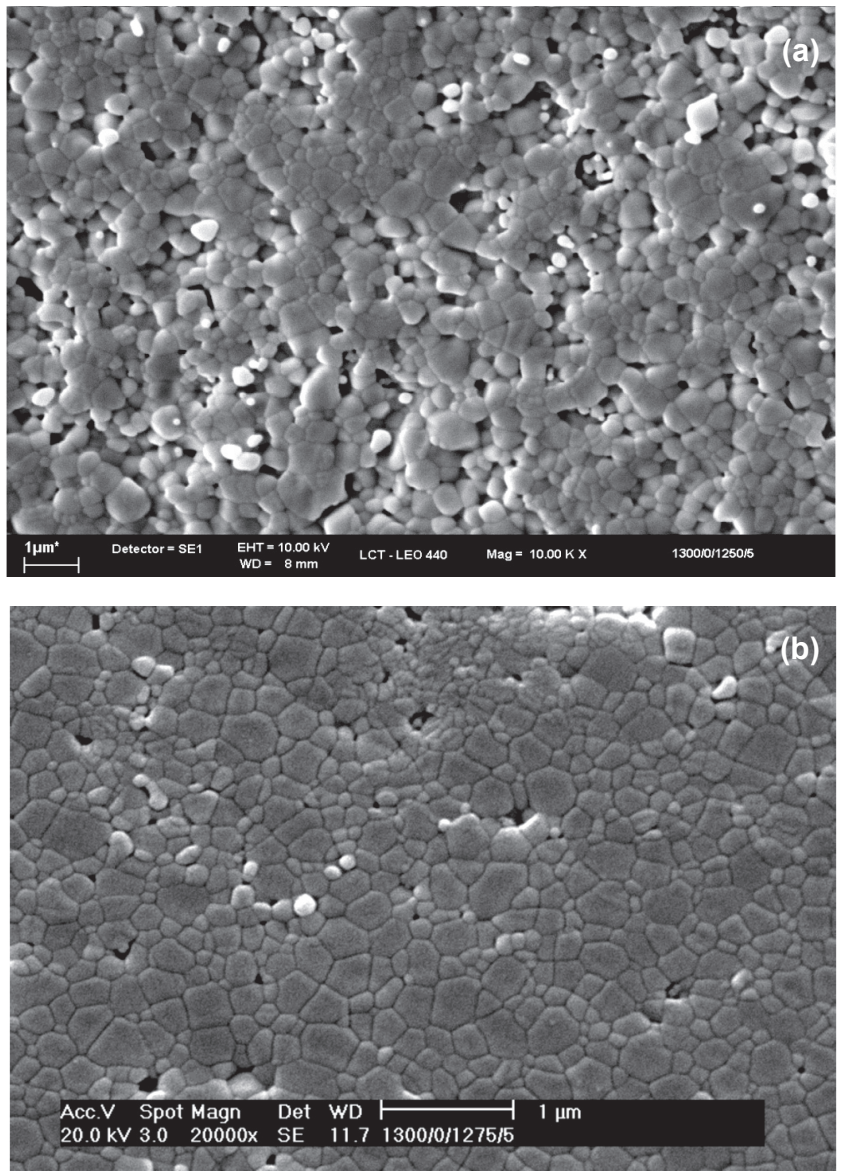

Figura 4: Micrografias obtidas em microscópio eletrônico de varredura de amostras sinterizadas em duas etapas (TSS) na temperatura $\mathrm{T}_{1}=1300{ }^{\circ} \mathrm{C}$ em diferentes temperaturas $\mathrm{T}_{2}$ : a) $1250{ }^{\circ} \mathrm{C}$ e b) $1275^{\circ} \mathrm{C}$, por tempo $\mathrm{t}_{2}=5 \mathrm{~h}$.

[Figure 4: Scanning electron microscopy micrographs of samples sintered by the two-stage process. $T_{1}=1300{ }^{\circ} \mathrm{C}$ and $T_{2}$ a) $1250{ }^{\circ} \mathrm{C}$, b) $\left.1275^{\circ} \mathrm{C} . t_{2}=5 \mathrm{~h}.\right]$

sinterizadas pelo processo de sinterização em duas etapas tradicional na temperatura $\mathrm{T}_{1}=1100{ }^{\circ} \mathrm{C}$ e segundo patamar $\mathrm{T}_{2}=1450^{\circ} \mathrm{C}$ com tempos $\mathrm{t}_{2}=1 \mathrm{~h}$ (Fig. 6a) e $5 \mathrm{~h}$ (Fig. 6b).

Para $t_{2}=1 \mathrm{~h}$ observam-se grãos micrométricos e pouca porosidade, que se torna praticamente desprezível para $\mathrm{t}_{2}=5 \mathrm{~h}$. Com o aumento de $\mathrm{t}_{2}$ ocorreu um crescimento no tamanho médio de grãos que foi superior àquele obtido para as amostras sinterizadas pelo método não-tradicional.

A Fig. 7 mostra, como exemplo, histogramas obtidos na análise da distribuição de tamanho de grãos para as amostras sinterizadas por ambos os métodos.

Para todas as amostras analisadas a população de grãos foi de aproximadamente 1000.

$\mathrm{Na}$ Tabela IV são listados os valores de tamanho médio de grãos determinados para as diferentes amostras. DV é o desvio padrão e mede a dispersão do tamanho médio de grãos.

Observa-se que para $\mathrm{T}_{1}=1300{ }^{\circ} \mathrm{C}$, não há aumento considerável no tamanho médio de grãos após o patamar isotérmico. Os valores de tamanho médio de grãos após $\mathrm{T}_{1}$ $=1450{ }^{\circ} \mathrm{C}$ e após $\mathrm{T}_{1}=1450{ }^{\circ} \mathrm{C}$ seguido de $\mathrm{T}_{2}=1300{ }^{\circ} \mathrm{C}$
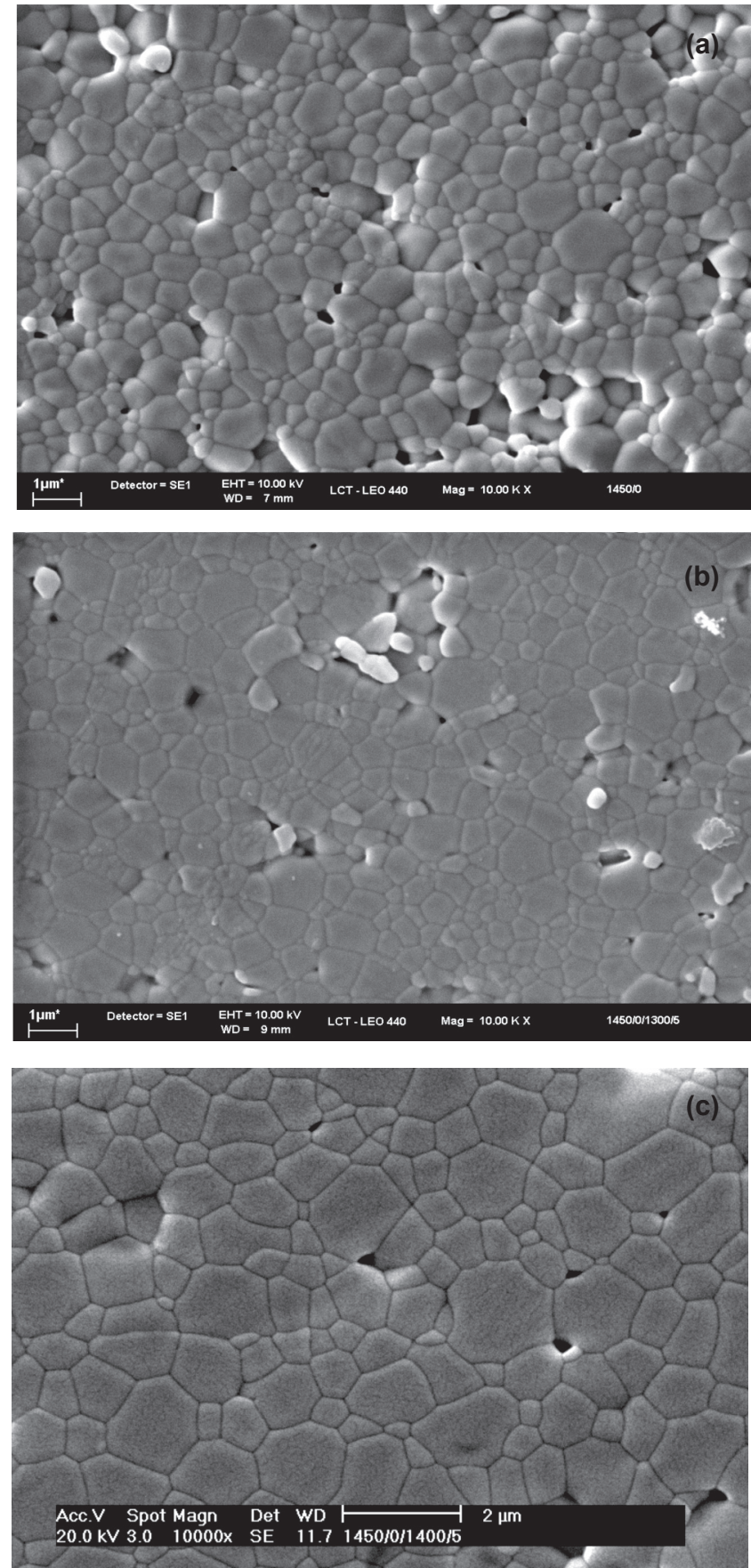

Figura 5: Micrografias obtidas em microscópio eletrônico de varredura de amostras sinterizadas a $1450{ }^{\circ} \mathrm{C}$ (a) e sinterizadas em duas etapas com $\mathrm{T}_{1}=1450{ }^{\circ} \mathrm{C}$ em diferentes temperaturas $\mathrm{T}_{2}: \mathrm{b}$ ) $1300{ }^{\circ} \mathrm{C}$ e c) $1400^{\circ} \mathrm{C}$, por tempo $\mathrm{t}_{2}=5 \mathrm{~h}$.

[Figure 5: Scanning electron microscopy micrographs of samples sintered at $1450{ }^{\circ} \mathrm{C}$ and by the two-stage method at $T_{1}=1450{ }^{\circ} \mathrm{C}$ and $T_{2}=$ b) $1300{ }^{\circ} \mathrm{C}$ and c) $1400{ }^{\circ} \mathrm{C}$, for $t_{2}=5 \mathrm{~h}$.]

por $t_{2}=5 \mathrm{~h}$ são essencialmente iguais mostrando que, para estas condições, não há crescimento de grãos na etapa final de sinterização.

No caso da sinterização em duas etapas tradicional, ocorre aumento no tamanho médio de grãos com o aumento do tempo do segundo patamar, como esperado. 

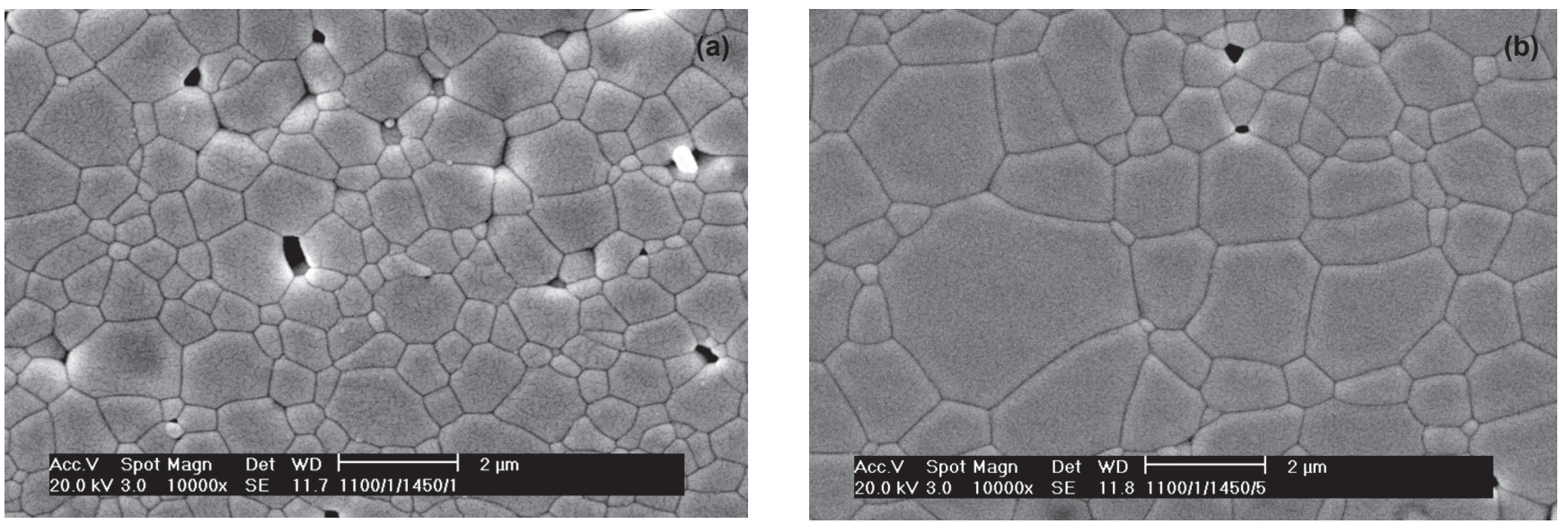

Figura 6: Micrografias obtidas em microscópio eletrônico de varredura de amostras sinterizadas pelo processo em duas etapas tradicional na temperatura $\mathrm{T}_{1}=1100^{\circ} \mathrm{C}$ e $\mathrm{T}_{2}=1450{ }^{\circ} \mathrm{C}$ em diferentes tempos $\mathrm{t}_{2}$ : a) $1 \mathrm{~h} \mathrm{e} \mathrm{b)} 5 \mathrm{~h}$.

[Figure 6: Scanning electron microscopy micrographs of samples sintered by the traditional two-stage method at $T_{1}=1100{ }^{\circ} \mathrm{C}$ and $T_{2}=$ $1450{ }^{\circ} \mathrm{C}$ for times $\left.t_{2}=a\right) 1 \mathrm{~h}$ and b) $5 \mathrm{~h}$.]
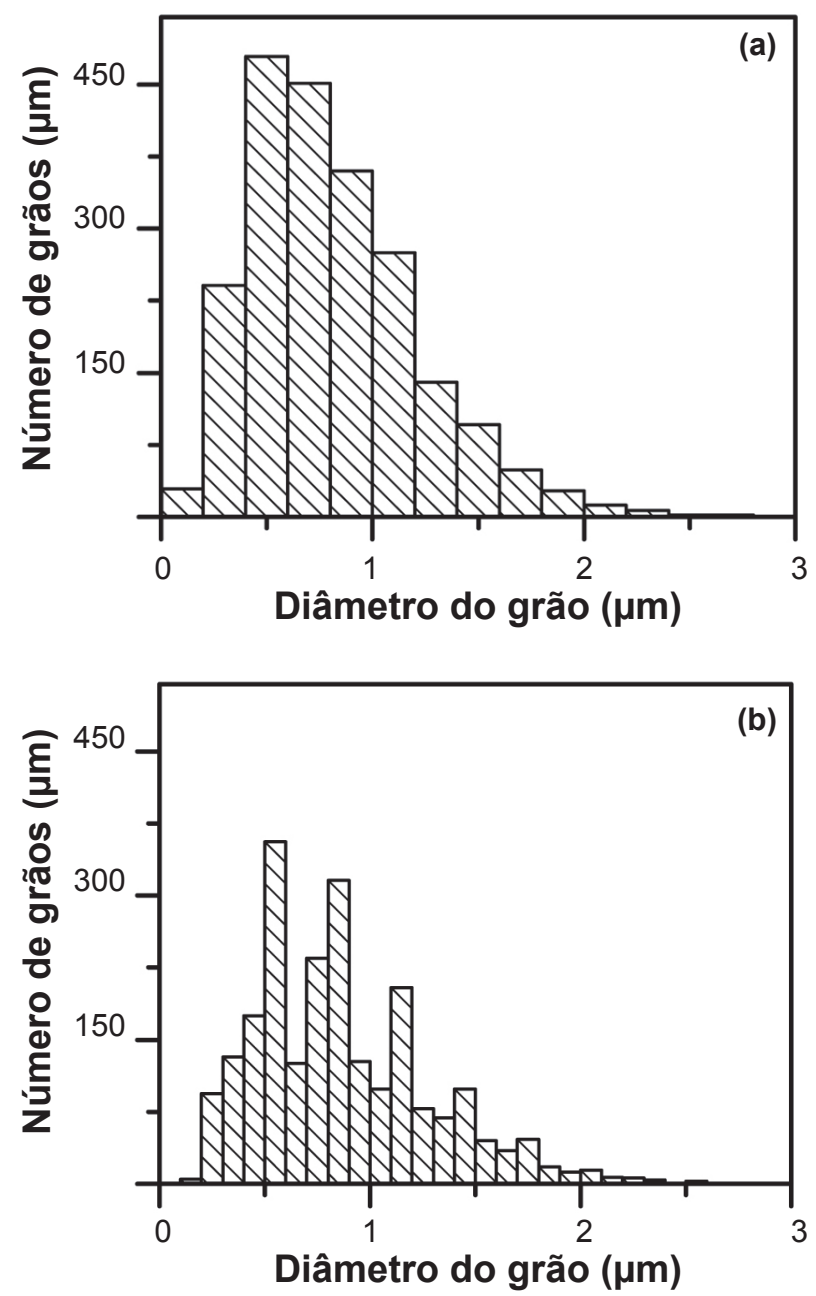

Figura 7: Histogramas da distribuição de tamanho de grãos das amostras sinterizadas pelos métodos (a) $\operatorname{TSS}\left(\mathrm{T}_{1}=1450{ }^{\circ} \mathrm{C}\right.$ e $\mathrm{T}_{2}=$ $\left.1300^{\circ} \mathrm{C}, \mathrm{t}_{2}=5 \mathrm{~h}\right) \mathrm{e}(\mathrm{b}) \mathrm{TSS}-\mathrm{t}\left(\mathrm{T}_{1}=1100{ }^{\circ} \mathrm{Ce} \mathrm{T}_{2}=1450{ }^{\circ} \mathrm{C}, \mathrm{t}_{2}=1 \mathrm{~h}\right)$. [Figure 7: Histograms of grain size distribution of samples sintered by (a) TSS $\left(T_{1}=1450{ }^{\circ} \mathrm{C}\right.$ e $T_{2}=1300{ }^{\circ} \mathrm{C}, t_{2}=5 \mathrm{~h}$ and (b) TSS-t $\left(T_{1}\right.$ $=1100{ }^{\circ} \mathrm{C}$ and $\mathrm{T}_{2}=1450{ }^{\circ} \mathrm{C}, t_{2}=1 \mathrm{~h}$ ) methods.]
Tabela IV - Tamanho médio de grão para as amostras sinterizadas pelo método TSS com $\mathrm{T}_{1}=1300^{\circ} \mathrm{C}$ e $\mathrm{T}_{1}=1450^{\circ} \mathrm{C}$ em diferentes temperaturas $\mathrm{T}_{2}$ e $\mathrm{t}_{2}, \mathrm{e}$ amostras sinterizadas pelo método TSS-t com $\mathrm{T}_{1}=1100^{\circ} \mathrm{C}$ e $\mathrm{T}_{2}=1450^{\circ} \mathrm{C}$ em diferentes tempos $\mathrm{t}_{2}$. $\mathrm{DV}=$ dispersão no valor do tamanho de grão.

[Table IV - Average grain size of samples sintered by the TSS method with $T_{1}=1300{ }^{\circ} \mathrm{C}$ and $T_{1}=1450{ }^{\circ} \mathrm{C}$, and different $T_{2}$ and $t_{2}$, and for samples sintered by the TSS- $t$ method with $T_{1}=$ $1100^{\circ} \mathrm{C}$ and $T_{2}=1450{ }^{\circ} \mathrm{C}$ for several $t_{2} . S D=$ dispersion of the average grain size.]

\begin{tabular}{ccc}
\hline $\begin{array}{c}\text { Temperatura / Tempo } \\
\left({ }^{\circ} \mathrm{C} / \mathrm{h}\right)\end{array}$ & $\begin{array}{c}\text { Tamanho médio de grão } \\
(\mu \mathrm{m})\end{array}$ & $\mathrm{DV}$ \\
\hline $1300 / 0+1250 / 5$ & 0,54 & 0,23 \\
$1300 / 0+1250 / 10$ & 0,58 & 0,27 \\
$1300 / 0+1275 / 5$ & 0,58 & 0,27 \\
$1300 / 0+1275 / 10$ & 0,67 & 0,34 \\
$1450 / 0$ & 0,85 & 0,41 \\
$1450 / 0+1300 / 5$ & 0,85 & 0,39 \\
$1450 / 0+1350 / 5$ & 0,95 & 0,53 \\
$1450 / 0+1400 / 5$ & 1,30 & 0,67 \\
$1450 / 0+1425 / 5$ & 1,51 & 0,70 \\
$1100 / 1+1450 / 0$ & 0,88 & 0,46 \\
$1100 / 1+1450 / 1$ & 1,13 & 0,56 \\
$1100 / 1+1450 / 2$ & 1,48 & 0,89 \\
$1100 / 1+1450 / 5$ & 1,78 & 0,93 \\
$1200 / 1+1450 / 5$ & 1,72 & 0,88 \\
\hline
\end{tabular}

As Figs. 8 e 9 mostram a variação do tamanho médio de grãos em função do tempo de sinterização e da densidade relativa, respectivamente, para amostras sinterizadas por ambos os métodos, para fins comparativos.

O crescimento de grãos é acelerado nas amostras sinterizadas pelo método tradicional (Fig. 8) comparativamente ao método TSS.

Na Fig. 9, os números acima dos símbolos correspondem ao tempo $t_{2}$ de sinterização. 


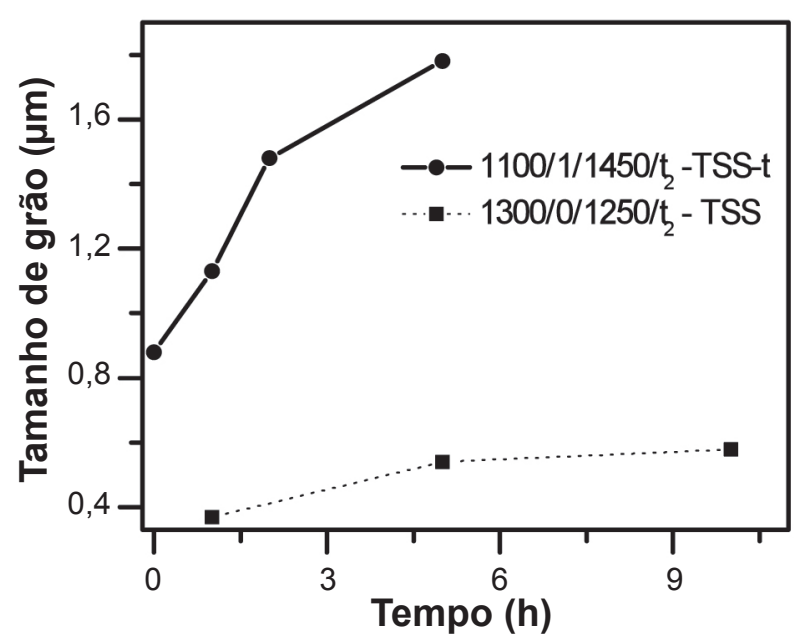

Figura 8: Variação do tamanho médio de grãos para amostras sinterizadas em duas etapas (TSS) $\operatorname{com~} \mathrm{T}_{1}=1300^{\circ} \mathrm{Ce} \mathrm{T}_{2}=1250{ }^{\circ} \mathrm{C}$, e sinterizadas em duas etapas tradicional (TSS-t) com $\mathrm{T}_{1}=1100^{\circ} \mathrm{C} \mathrm{e}$ $\mathrm{T}_{2}=1450{ }^{\circ} \mathrm{C}$ em função do $\mathrm{t}_{2}$.

[Figure 8: Grain size evolution of samples sintered by the TSS method with $T_{1}=1300{ }^{\circ} \mathrm{C}$ and $T_{2}=1250{ }^{\circ} \mathrm{C}$, and sintered by the TSS-t method with $T_{1}=1100{ }^{\circ} \mathrm{C}$ and $T_{2}=1450{ }^{\circ} \mathrm{C}$ as a function of $\left.t_{2} \cdot\right]$

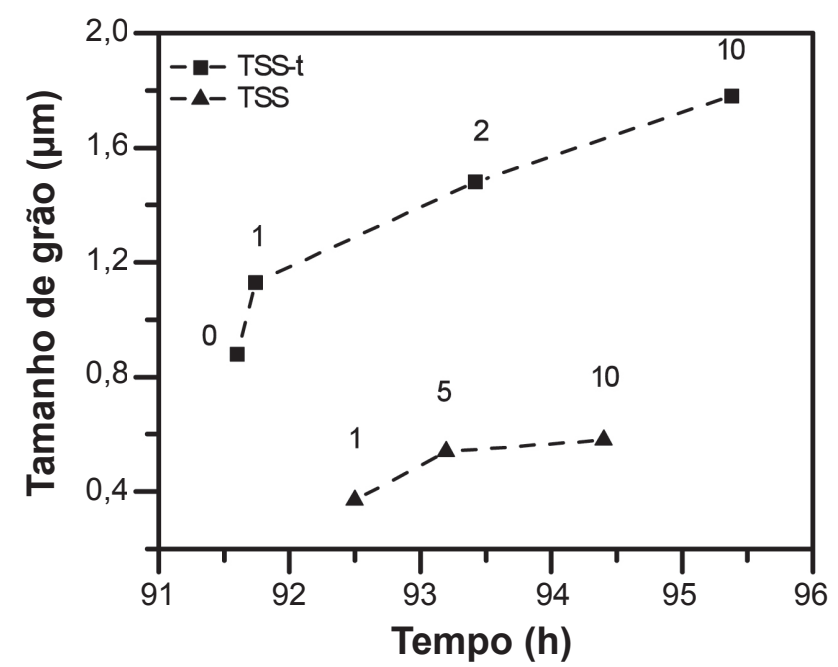

Figura 9: Variação do tamanho médio de grãos para as amostras sinterizadas em duas etapas (TSS) com $\mathrm{T}_{1}=1300^{\circ} \mathrm{C}$ e $\mathrm{T}_{2}=1250$ ${ }^{\circ} \mathrm{C}$ e sinterizadas em duas etapas tradicional (TSS-t) $\operatorname{com} \mathrm{T}_{1}=1100$ ${ }^{\circ} \mathrm{C}$ e $\mathrm{T}_{2}=1450{ }^{\circ} \mathrm{C}$, em função da densidade relativa.

[Figure 9: Grain size evolution of samples sintered by the TSS method with $T_{1}=1300{ }^{\circ} \mathrm{C}$ and $T_{2}=1250{ }^{\circ} \mathrm{C}$, and sintered by the TSS-t method with $T_{1}=1100{ }^{\circ} \mathrm{C}$ and $T_{2}=1450{ }^{\circ} \mathrm{C}$ as a function of relative density.]

O crescimento de grãos é acelerado nas amostras sinterizadas pelo método tradicional com densidade relativa superior a $91 \%$, enquanto que o método não tradicional proporciona um crescimento comparativamente lento, mesmo para densidades relativas superiores a $92 \%$. No método TSS o tamanho de grão é, em princípio, estabelecido pela temperatura $T_{1}$, enquanto para o método TSS-t a temperatura $T_{2}$ e o tempo $t_{2}$ são determinantes. No método em duas etapas a temperaturas $T_{1}$ e $T_{2}$ podem também determinar o crescimento (ou não) de grãos no estágio posterior [12]. Se $\mathrm{T}_{1}$ é comparativamente alta e $\mathrm{T}_{2}$ é próxima a $T_{1}$, nesta situação poderá ocorrer crescimento de grãos, ainda que limitado, na segunda etapa de sinterização.

Os resultados de microestrutura mostraram que apesar do método de sinterização em duas etapas não ter resultado em aumento da densificação da céria-samária, quando comparado com o método tradicional, houve redução significativa no tamanho médio de grãos. Este aspecto pode ser relevante para a melhoria das propriedades mecânicas deste eletrólito sólido.

\section{Condutividade elétrica}

A Fig. 10 mostra o comportamento da condutividade dos grãos, $\sigma_{g}$, para amostras sinterizadas em duas etapas com $T_{1}$ $=1300^{\circ} \mathrm{C}$, diferentes $\mathrm{T}_{2}$, e $\mathrm{t}_{2}=5 \mathrm{~h}$ e $10 \mathrm{~h}$.

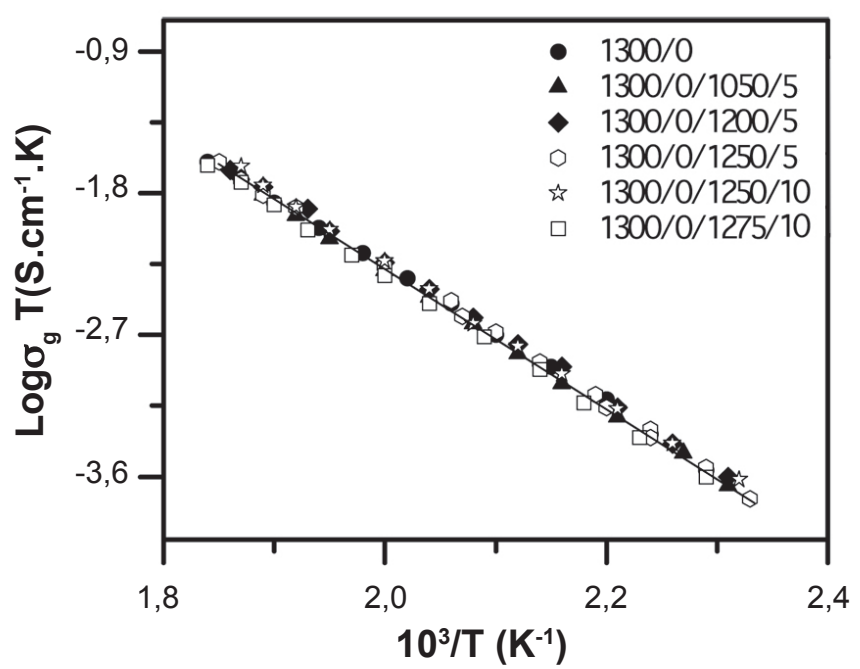

Figura 10: Gráficos de Arrhenius da condutividade elétrica dos grãos das amostras sinterizadas pelo método de duas etapas. $\mathrm{T}_{1}=$ $1300{ }^{\circ} \mathrm{C}$ e vários $\mathrm{T}_{2}$ com $\mathrm{t}_{2}=5$ e $10 \mathrm{~h}$.

[Figure 10: Arrhenius plots of grain electrical conductivities of samples sintered by the two-stage method. $T_{1}=1300{ }^{\circ} \mathrm{C}$ and several $T_{2}$ with $t_{2}=5$ and $10 \mathrm{~h}$.]

Observa-se que não há variação da condutividade dos grãos com o perfil de sinterização. Este resultado confirma que não há mudança na composição química dos grãos em decorrência dos tratamentos térmicos, que poderiam causar dissolução de impurezas originalmente presentes nos contornos de grão, principalmente naqueles realizados por tempos mais longos.

Resultado similar foi obtido para as amostras sinterizadas a $\mathrm{T}_{1}=1450{ }^{\circ} \mathrm{C}$, diferentes $\mathrm{T}_{2}$, e $\mathrm{t}_{2}=5 \mathrm{~h}$ (Fig. 11).

Estes resultados também mostram que para as condições de sinterização empregadas não há, ao menos de forma significativa, segregação do samário para a região dos contornos de grão, pois isto também causaria diminuição da condutividade intragranular.

As Figs. 12 e 13 mostram o comportamento da condutividade elétrica dos contornos de grão, $\sigma_{\text {cg }}$, para 


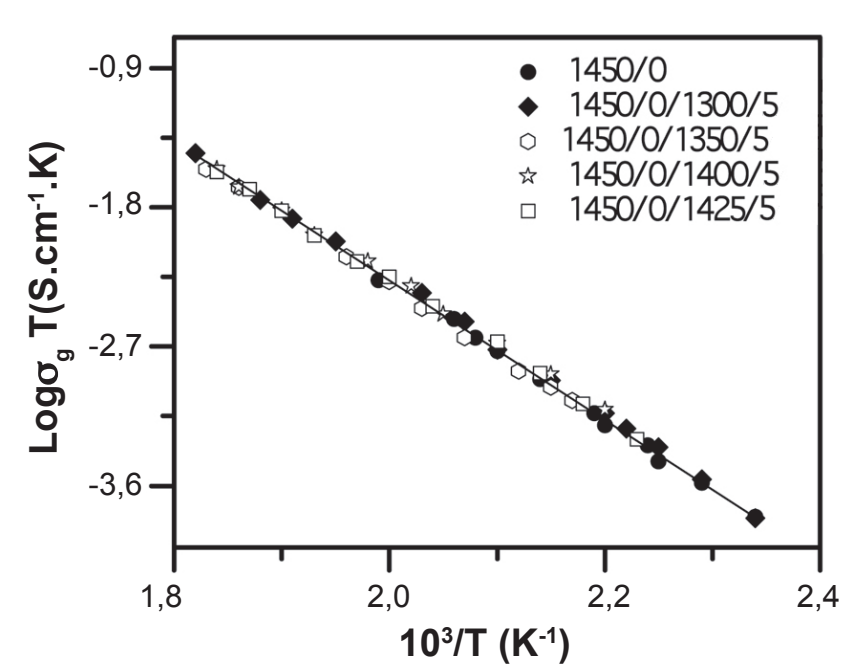

Figura 11: Gráficos de Arrhenius da condutividade elétrica dos grãos das amostras sinterizadas pelo método de duas etapas. $\mathrm{T}_{1}=$ $1450{ }^{\circ} \mathrm{C}$ e vários $\mathrm{T}_{2} \operatorname{comt}_{2}=5 \mathrm{~h}$.

[Figure 11: Arrhenius plots of grain electrical conductivities of samples sintered by the two-stage method. $T_{1}=1450{ }^{\circ} \mathrm{C}$ and several $T_{2}$ with $t_{2}=5 \mathrm{~h}$.]

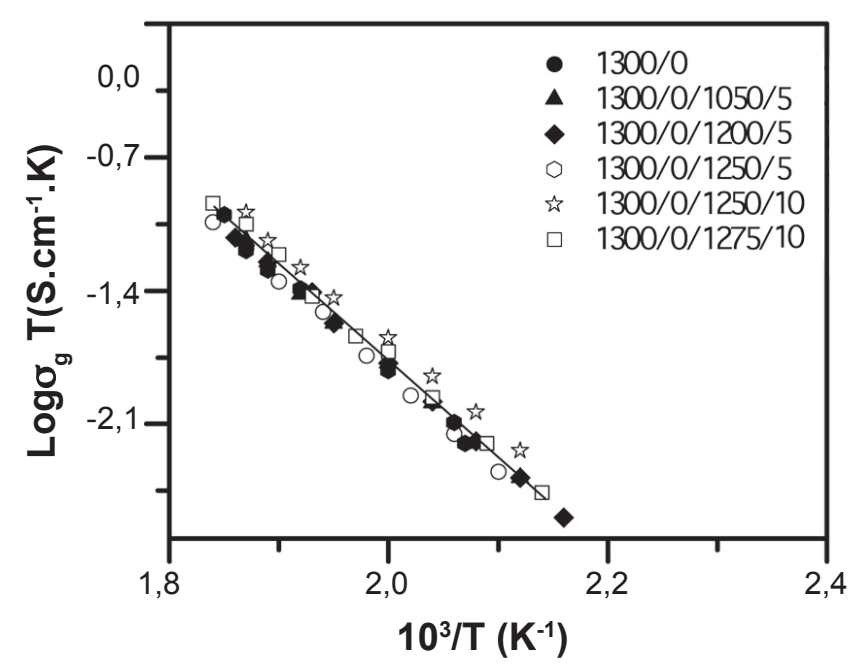

Figura 12: Gráficos de Arrhenius da condutividade elétrica dos contornos de grão das amostras sinterizadas pelo método de duas etapas. $\mathrm{T}_{1}=1300^{\circ} \mathrm{C}$ e vários $\mathrm{T}_{2}$ com $\mathrm{t}_{2}=5 \mathrm{~h} \mathrm{e} 10 \mathrm{~h}$.

[Figure 12: Arrhenius plots of grain boundary conductivities of samples sintered by the two-stage method. $T_{1}=1300{ }^{\circ} \mathrm{C}$ and several $T_{2}$ with $t_{2}=5 \mathrm{~h}$ and $10 \mathrm{~h}$.]

amostras sinterizadas em duas etapas com $\mathrm{T}_{1}=1300^{\circ} \mathrm{C}$ e $\mathrm{T}_{1}$ $=1450{ }^{\circ} \mathrm{C}$, com diferentes $\mathrm{T}_{2}$ e $\mathrm{t}_{2}$.

Para $\mathrm{T}_{1}=1300^{\circ} \mathrm{C}$ (Fig. 12) a condutividade dos contornos de grão praticamente independe da temperatura e do tempo de patamar da segunda etapa de sinterização. É importante salientar que não foi observada variação significativa no tamanho médio de grãos (dentro do erro experimental) para estas condições de sinterização. Quando há aumento no tamanho dos grãos, ou seja, diminuição na área total ocupada pelos contornos de grão, aumenta a condutividade do contorno de grão. Isto acontece, pois os contornos de

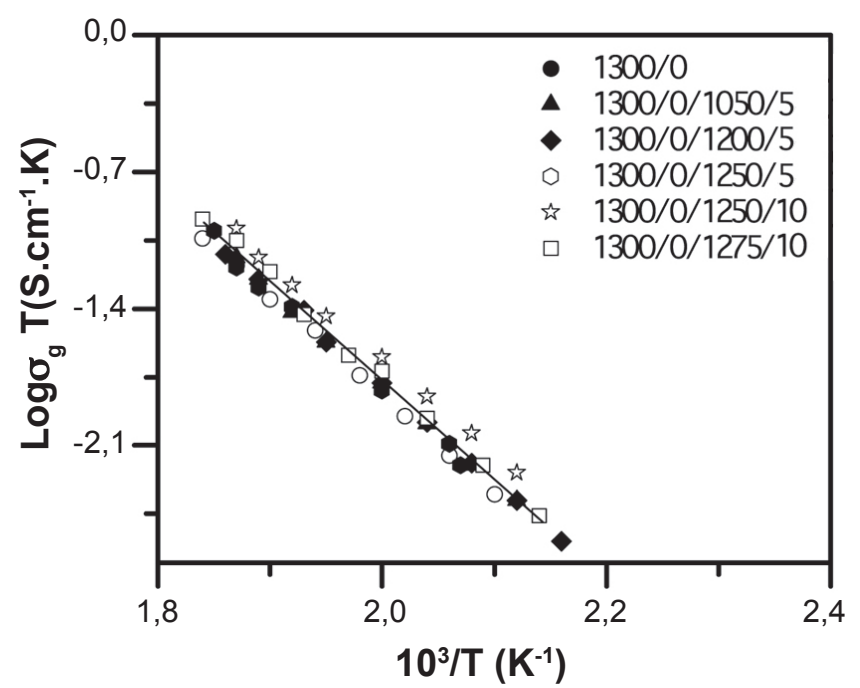

Figura 13: Gráficos de Arrhenius da condutividade elétrica dos contornos de grão das amostras sinterizadas pelo método de duas etapas. $\mathrm{T}_{1}=1450^{\circ} \mathrm{C}$ e vários $\mathrm{T}_{2} \operatorname{com} \mathrm{t}_{2}=5 \mathrm{~h}$.

[Figure 13: Arrhenius plots of grain boundary electrical conductivities of samples sintered by the two-stage method. $T_{1}=$ $1450{ }^{\circ} \mathrm{C}$ and several $T_{2}$ with $t_{2}=5 \mathrm{~h}$.]

grão oferecem resistência à migração dos portadores de carga iônicos, isto é, atuam como uma barreira adicional para a difusão.

Os resultados obtidos para a condutividade dos contornos de grão, com $\mathrm{T}_{1}=1450{ }^{\circ} \mathrm{C}$ (Fig. 13) são similares àqueles obtidos para $\mathrm{T}_{1}=1300{ }^{\circ} \mathrm{C}$ (Fig. 12). As pequenas variações observadas nesses gráficos estão dentro do erro experimental de análise dos dados.

As Figs. 14 e 15 mostram, respectivamente, o comportamento da condutividade dos grãos e dos contornos de grão para amostras sinterizadas pelo método em duas etapas tradicional, com diferentes $\mathrm{T}_{1}$, e temperatura e tempo

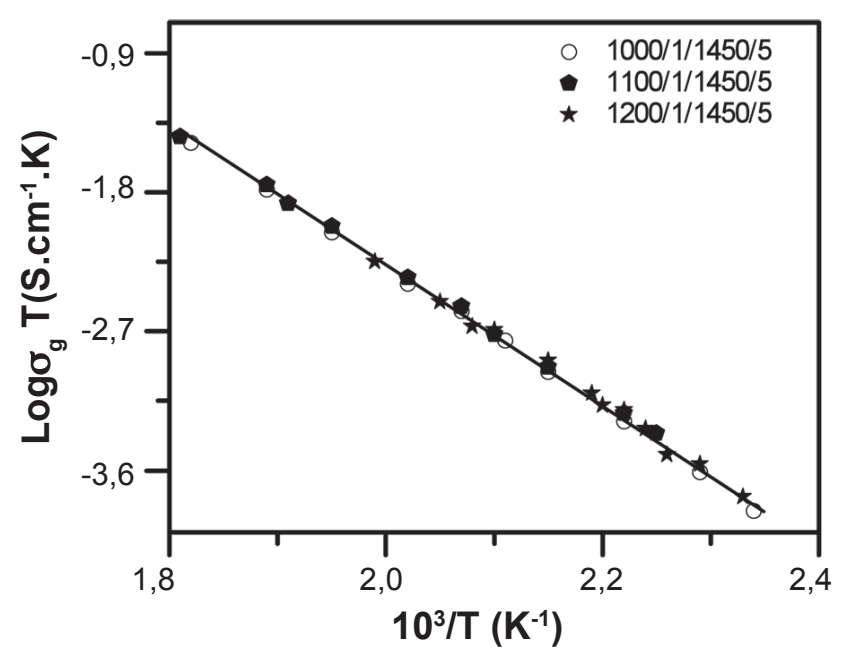

Figura 14: Gráficos de Arrhenius da condutividade elétrica dos grãos das amostras sinterizadas pelo método tradicional de duas etapas para diferentes $\mathrm{T}_{1}$ e $\mathrm{T}_{2}=1450{ }^{\circ} \mathrm{C}, \mathrm{t}_{2}=5 \mathrm{~h}$.

[Figure 14: Arrhenius plots of grain electrical conductivities of samples sintered by the traditional two-stage method for different $T_{1}$ and $\left.T 2=1450{ }^{\circ} \mathrm{C}, t_{2}=5 \mathrm{~h}.\right]$ 


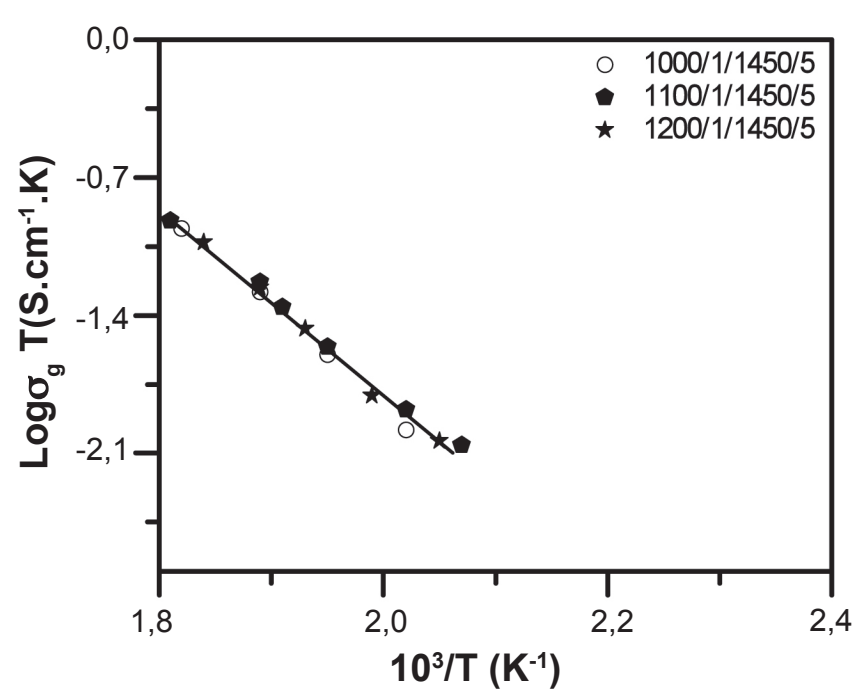

Figura 15: Gráficos de Arrhenius da condutividade elétrica dos contornos de grão das amostras sinterizadas pelo método tradicional de duas etapas para diferentes $\mathrm{T}_{1} \mathrm{e} \mathrm{T}_{2}=1450{ }^{\circ} \mathrm{C}, \mathrm{t}_{2}=5 \mathrm{~h}$.

[Figure 15: Arrhenius plots of grain electrical boundary conductivities of samples sintered by the traditional two-stage method for different $T_{1}$ and $T_{2}=1450^{\circ} \mathrm{C}, t_{2}=5 \mathrm{~h}$.]

do segundo patamar iguais a $1450{ }^{\circ} \mathrm{C}$ e $5 \mathrm{~h}$, respectivamente.

Não há variação da condutividade dos grãos com a temperatura de sinterização, como esperado, de forma similar ao obtido para amostras sinterizadas pelo método em duas etapas (Figs. 10 e 11).

Para as amostras sinterizadas pelo método de duas etapas tradicional, a condutividade dos contornos de grão também não variou com o aumento de $\mathrm{T}_{1}$. Isto mostra que as condições utilizadas na segunda etapa de sinterização determinam a condutividade elétrica da céria-samária, e que a variação obtida no tamanho médio de grãos é insuficiente para causar alterações significativas na condutividade intergranular.

\section{CONCLUSÕES}

Valores elevados de densidade ( $>92 \%$ da densidade teórica) foram obtidos para a $\mathrm{Ce}_{0,8} \mathrm{Sm}_{0,2} \mathrm{O}_{1,9}$ comercial sinterizada por ambos os método de duas etapas. Independente do método foi necessário utilizar uma temperatura igual ou superior a 1300 ${ }^{\circ} \mathrm{C}$ para obter densificação aceitável. O método de sinterização em duas etapas não foi efetivo para produzir uma densificação superior ao tradicional.

A sinterização em duas etapas proporcionou menor tamanho de grãos quando comparada com o método tradicional, pois o crescimento de grãos é mais rápido neste último.

A condutividade elétrica, tanto intragranular quanto intergranular, independe da forma de sinterização e do perfil temperatura-tempo, nas condições estudadas.

\section{AGRADECIMENTOS}

Os autores agradecem à FAPESP, CNPq e CNEN pelo apoio financeiro, ao CNPq pela bolsa de mestrado de S. L.
Reis, e ao Centro de Células a Combustível e Hidrogênio do IPEN pela medida da retração linear.

\section{REFERÊNCIAS}

[1] H. Inaba, H. Tagawa, Solid State Ionics 83 (1996) 1-16.

[2] Y. Yoshimura, Y. Hirata, S. Sameshima, T. Horit, J. Ceram. Process. Res. 5 (2004) 327-330.

[3] J. Van Herle, T. Horita, T. Kawada, N. Sakai, H. Yokokawa, M. Dokiya, Solid State Ionics 86-88 (1996) 1255-1258.

[4] W. Huang, P. Shuk, M. Greenblatt, Chem. Mater. 9 (1997) 2240-2245.

[5] W. Huang, P. Shuk, M. Greenblatt, Solid State Ionics 100 (1997) 23-27.

[6] C. Peng, X. Cheng, J. Mater. Sci.- Mater. Electron. 13 (2002) 757-762.

[7] S. Zha, C. Xia, J. Power Sources 115 (2003) 44-48.

[8] B. C. H. Steele, K. Zheng, R. A. Rudkin, N. Kiratzis, M. Christie, Proc. $4^{\text {th }}$ Int. Symp. Solid Oxide Fuel Cells, Yokohama, Japan (1995) 1028.

[9] V. Esposito, E. Traversa, J. Am. Ceram. Soc. 91 (2008) 1037-1051.

[10] M. G. Bellino, D. G. Lamas, N. W. de Reca, Adv. Funct. Mater. 16 (2006) 107-113.

[11] U. Anselmi-Tamburini, F. Maglia, G. Chiodelli, A. Tacca, G. Spinolo, P. Riello, S. Bucella, Z. A. Munir, Adv. Funct. Mater. 16 (2006) 2363-2368.

[12] I.-W. Chen, X.-W. Wang, Nature 404 (2000) 168-171. [13] Y.-I. Lee, Y.-W. Kim, M. Mitomo, D.-Y. Kim, J. Am. Ceram. Soc. 86 (2003) 1803-1805.

[14] Y.-I. Lee, Y.-W. Kim, M. Mitomo, D.-Y. Kim, J. Mater. Sci. 39 (2004) 3801-3803.

[15] H. T. Kim, Y. H. Han, Ceram. Int. 30 (2004) 1719-1723.

[16] H.-D. Kim, Y.-J. Park, B.-D. Han, M.-Q. Park, W.-T. Bae, Y.-W. Kim, H.-T. Lin, P. F. Becher, Scripta Mater. 54 (2006) 615-619.

[17] K. Bodisová, P, Sajgalik, D. Galusek, P. Svancarek, J. Am. Ceram. Soc. 90 (2007) 330-332.

[18] M. Mazaheri, A. M. Zahedi, S. K. Sadrnezhaadt, J. Am. Ceram. Soc. 91 (2008) 56-63.

[19] J. Binner, K. Annapoorani, A. Paul, I. Santacruz, B. Vaidhyanathan, J. Eur. Ceram. Soc. 28 (2008) 973-977.

[20] D.-S. Kim, J.-H. Lee, R. J. Sung, W. W. Kim, H. S. Kim, J. S. Park, J. Eur. Ceram. Soc. 27 (2007) 3629-3632.

[21] H.-D. Kim, Y.-J. Park, B.-D. Han, M.-W. Park, W.-T. Bae, Y.-W. Kim, H.-T. Lin, P. F. Becher, Scripta Mater. 54 (2006) 615-619.

[22] J. Li, Y. Ye, J. Am. Ceram Soc. 89 (2006) 139-143.

[23] X. -H. Wang, X. -Y. Deng, Hai-Lin Bai, H. Zhou, Wei-Guo Qu, L. -T.Li, I. -W. Chen, J. Am. Ceram. Soc. 89 (2006) 438-443.

[24] C. M. Lapa, D. P. Ferreira de Souza, F. M. L. Figueiredo, F. M. B. Marques, J. Power Sources 187 (2009) 204-208.

[25] M.-Y. Chu, L. C. Jonghe, J. Am. Ceram. Soc. 74 (1991) 2902-2911.

[26] F. J. T. Lin, L. C. Jonghe, M. N. Rahaman, J. Am. 
Ceram. Soc. 80 (1997) 2269-2277.

[27] F. J. T. Lin, L. C. Jonghe, M. N. Rahaman, J. Am. Ceram. Soc. 80 (1997) 2891-2896.
[28] W. D. Kingery, H. K. Bowen, D. R. Uhlmann, Introduction to ceramics, John Wiley, New York, EUA, 1975.

(Rec. 25/08/2010, Ac. 22/01/2011) 